\title{
Modeling of Shear Localization in Materials
}

\author{
D. Lesuer \\ M. LeBlanc \\ B. Riddle \\ B. Jorgensen
}

February 11, 1998

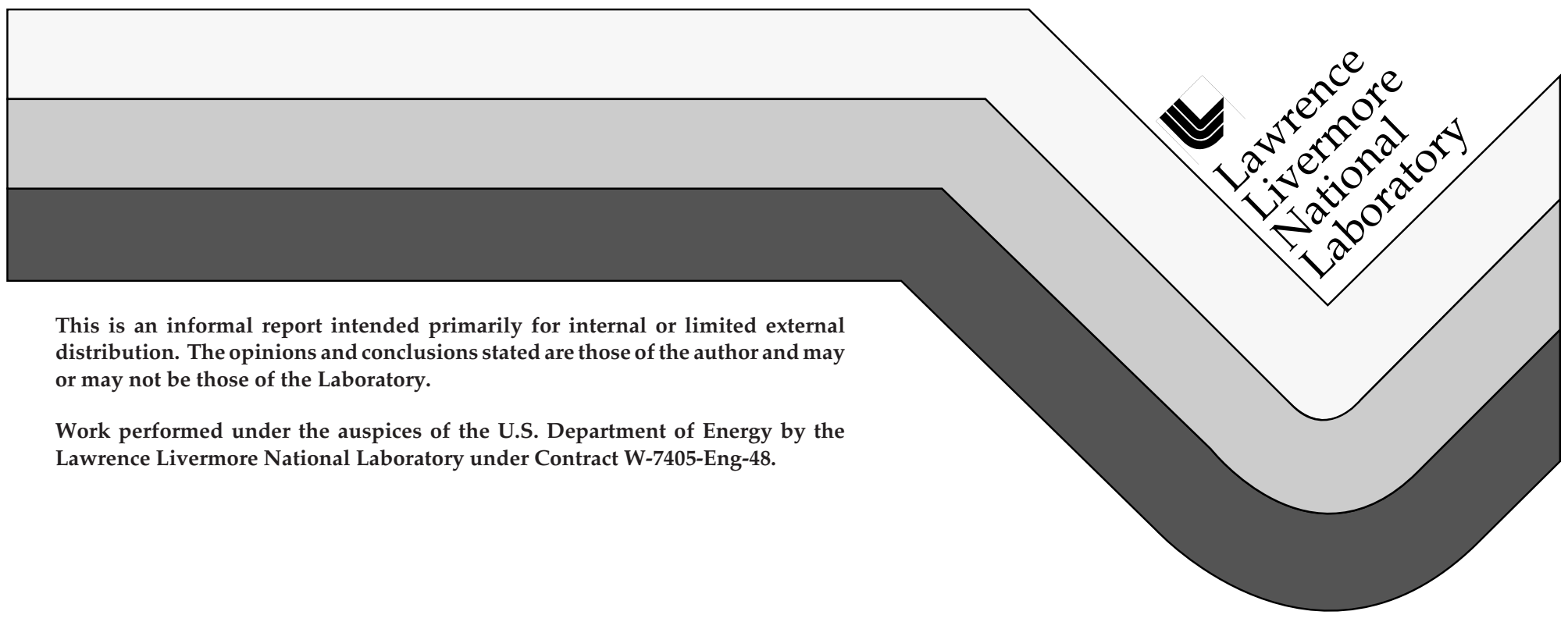




\section{DISCLAIMER}

This document was prepared as an account of work sponsored by an agency of the United States Government. Neither the United States Government nor the University of California nor any of their employees, makes any warranty, express or implied, or assumes any legal liability or responsibility for the accuracy, completeness, or usefulness of any information, apparatus, product, or process disclosed, or represents that its use would not infringe privately owned rights. Reference herein to any specific commercial product, process, or service by trade name, trademark, manufacturer, or otherwise, does not necessarily constitute or imply its endorsement, recommendation, or favoring by the United States Government or the University of California. The views and opinions of authors expressed herein do not necessarily state or reflect those of the United States Government or the University of California, and shall not be used for advertising or product endorsement purposes.

This report has been reproduced directly from the best available copy.

Available to DOE and DOE contractors from the Office of Scientific and Technical Information

P.O. Box 62, Oak Ridge, TN 37831

Prices available from (615) 576-8401, FTS 626-8401

Available to the public from the

National Technical Information Service

U.S. Department of Commerce 5285 Port Royal Rd.,

Springfield, VA 22161 
ME Tech Base Annual Report

\title{
Modeling of Shear Localization in Materials
}

\author{
Don Lesuer \\ Mary LeBlanc \\ Manufacturing and Materials Engineering Division \\ Bob Riddle \\ Bert Jorgensen \\ Defense Technologies Engineering Division
}

\begin{abstract}
The deformation response of a Ti alloy, Ti-6Al-4V, has been studied during shear localization. The study has involved well-controlled laboratory tests involving a double-notch shear sample. The results have been used to provide a comparison between experiment and the predicted response using DYNA2D and two material models (the Johnson-Cook model and an isotropic elastic-plastichydrodynamic model). The work will serve as the basis for the development of a new material model which represents the different deformation mechanisms active during shear localization.
\end{abstract}




\section{Background}

Shear localization. Shear localization is a common deformation and failure process that occurs when deformation is concentrated in a single macroscopic shear zone. It can occur in many materials at moderate and high strain rates due to localized, adiabatic heat production. Zener and Holoman [1] have estimated that during simple punching of a metal plate the temperature increase in a shear band due to adiabatic heat production can be as high as $1000^{\circ} \mathrm{C}$. This increase in temperature produces thermal softening in the band and localization of plastic flow.

Shear localization is observed in many material processing operations as well as during the in-service performance of materials. Typical material processing operations, in which shear localization is observed, include material cutting, numerous forming operations (including rolling and forging) and material polishing. In many cases, the success or failure of these processing operations is defined by shear localization. It is typically observed during the ballistic penetration and perforation of armor materials, the performance of munitions and during explosive fragmentation - all problems of interest to Laboratory programs. However, despite its common occurrence and importance, shear localization remains poorly understood and is difficult to accurately model. Much of this difficulty arises from the large strains and adiabatic heat produced which, in turn, causes increases in temperature with resulting changes in material microstructure, material properties and deformation mechanisms. Large changes in strain rate are also produced.

Objectives. Material models which can adequately represent the deformation response during shear localization must account for large strains (and the resulting strain hardening or softening), as well as large changes in strain rate and temperature. Several models have been developed which can represent, to varying degrees, the high rate deformation response of materials. Examples include models by Johnson-Cook (JC) [2], Zerilli-Armstrong (ZA) [3, 4] and Follansbee-Kocks (mechanical threshold stress model) [5]. Two of these models ( $\mathrm{JC}$ and $\mathrm{ZA}$ ) have been introduced into the DYNA codes. Of these two models, the JC model is much more widely used primarily because of the availability of material constants used in the constitutive equations.

The objective of this project was to critically assess the ability of existing material models to represent the deformation response of materials during shear localization. We have done this using well-controlled laboratory experiments involving a double-notch shear sample. The experimental results have been compared with the predictions of the DYNA2D code using the JC model as well as an isotropic elastic-plastic-hydrodynamic (EPH) model commonly used for 
large strain problems. The work will serve as the basis for the development of a new material model which represents the different deformation mechanisms active during shear localization.

\section{Material Models}

The formulation for the $\mathrm{JC}$ model is empirically based and represents the flow stress with an equation of the form,

$$
\sigma=\left[\mathrm{A}+\mathrm{B} \varepsilon^{\mathrm{n}}\right]\left[1+\mathrm{Cln} \varepsilon^{*}\right]\left[1-\mathrm{T}^{*}\right]
$$

where $\sigma$ is the effective stress, $\varepsilon$ is the effective plastic strain, $\dot{\varepsilon}^{*}$ is the normalized effective plastic strain rate (typically normalized to a strain rate of $1.0 \mathrm{~s}^{-1}$ ), $\mathrm{T}^{*}$ is the homologous temperature, $n$ is the work hardening exponent and $A, B, C$ and $m$ are constants. The values of $A, B, C, n$ and $m$ are determined from an empirical fit of flow stress data (as a function of strain, strain rate and temperature) to Eqn. (1). For shear localization problems, we can assume that an arbitrary percentage of the plastic work done during deformation produces heat in the deforming material. For many materials, $100 \%$ of the plastic work becomes heat in the material. Thus the temperature used in Eqn. (1) can be derived from the increase in temperature according to the following expression

$$
\Delta \mathrm{T}=\frac{\alpha \mathrm{B}}{\rho \mathrm{c}(\mathrm{n}+1)} \varepsilon^{\mathrm{n}+1}
$$

where $\Delta T$ is the temperature increase, $\alpha$ is the percentage of plastic work transformed to heat, $\mathrm{C}$ is the heat capacity and $\rho$ is the density.

The EPH model uses an arbitrary effective stress - effective plastic strain curve, while a tensile cutoff pressure is defined for the principal stress spall criterion. A linear polynomial was chosen to define the hydrostatic equation of state. Material properties were derived from handbook data. The model is a popular choice for large strain plasticity problems. However, it does not account for strain rate or temperature effects and thus its accuracy for predicting deformation response during shear localization is largely unknown. 


\section{Experiments}

The double-notch shear sample, which is shown schematically in Fig. 1, is designed to produce a homogeneous strain state of pure shear in the gage section of the sample at a reasonably constant displacement velocity. Deformation in the gage section becomes localized and adiabatic shear can result. The samples were loaded using a split Hopkinson pressure bar (SHPB) apparatus and data was obtained at strain rates of $10^{-3}$ to $10^{-4} \mathrm{~s}^{-1}$. A schematic diagram of this apparatus is shown in Fig. 2. In the SHPB tests, the strain histories for the incident $\left(\varepsilon_{1}(\mathrm{t})\right)$ and transmitted waves $\left(\varepsilon_{\mathrm{T}}(\mathrm{t})\right)$ were measured and analyzed to determine the nominal shear stress - strain - strain rate

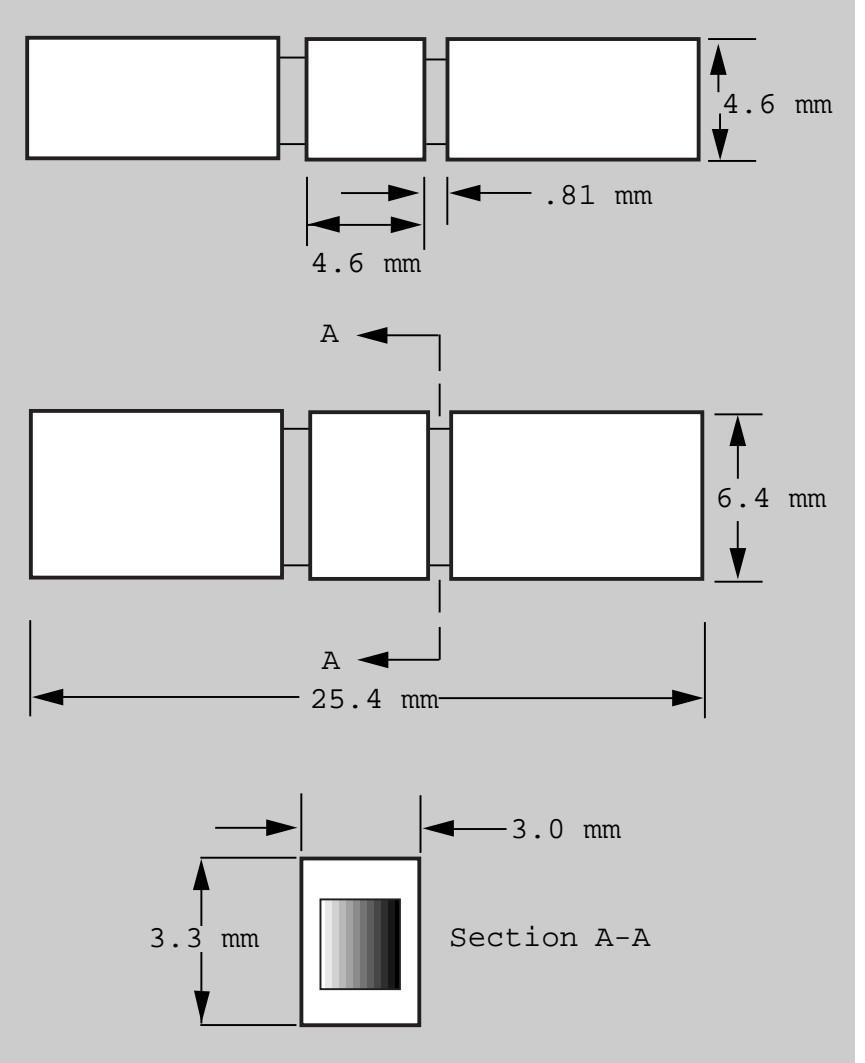

Fig. 1. Double-notch shear specimen used in this study. response of the sample during the shear test. The stress and strain rate response were calculated from the following expressions.

$$
\begin{gathered}
\tau(\mathrm{t})=\mathrm{E} \frac{\mathrm{A}_{\mathrm{o}}}{\mathrm{A}} \varepsilon_{\mathrm{T}}(\mathrm{t}) \\
\dot{\gamma}(\mathrm{t})=\frac{-2 \mathrm{C}_{0}}{\mathrm{~L}} \varepsilon_{\mathrm{R}}(\mathrm{t})
\end{gathered}
$$

and

with

$$
\varepsilon_{\mathrm{I}}(\mathrm{t})+\varepsilon_{\mathrm{R}}(\mathrm{t})=\varepsilon_{\mathrm{T}}(\mathrm{t})
$$

where $\tau(t)$ is the shear stress, $E$ is the elastic modulus of the bar, $A_{0}$ is the crosssectional area of the bar, $A$ is the specimen shear area, $\gamma(t)$ is the shear strain rate, $C_{o}$ is the longitudinal sound velocity in the bar, $L$ is the gage length and $\varepsilon_{R}(t)$ 
is the reflected strain in the bar. The resulting strain in the sample $(\varepsilon(\mathrm{t}))$ was obtained by integrating the strain rate history.

$$
\gamma(t)=\int_{t_{0}}^{t} \dot{\gamma} d t
$$

During FY97, experiments and simulations of the double-notch shear experiment were done for a Ti alloy, Ti-6Al-4V. The tests were done at a number of different projectile velocities to get experimental results over a range of strain rates.

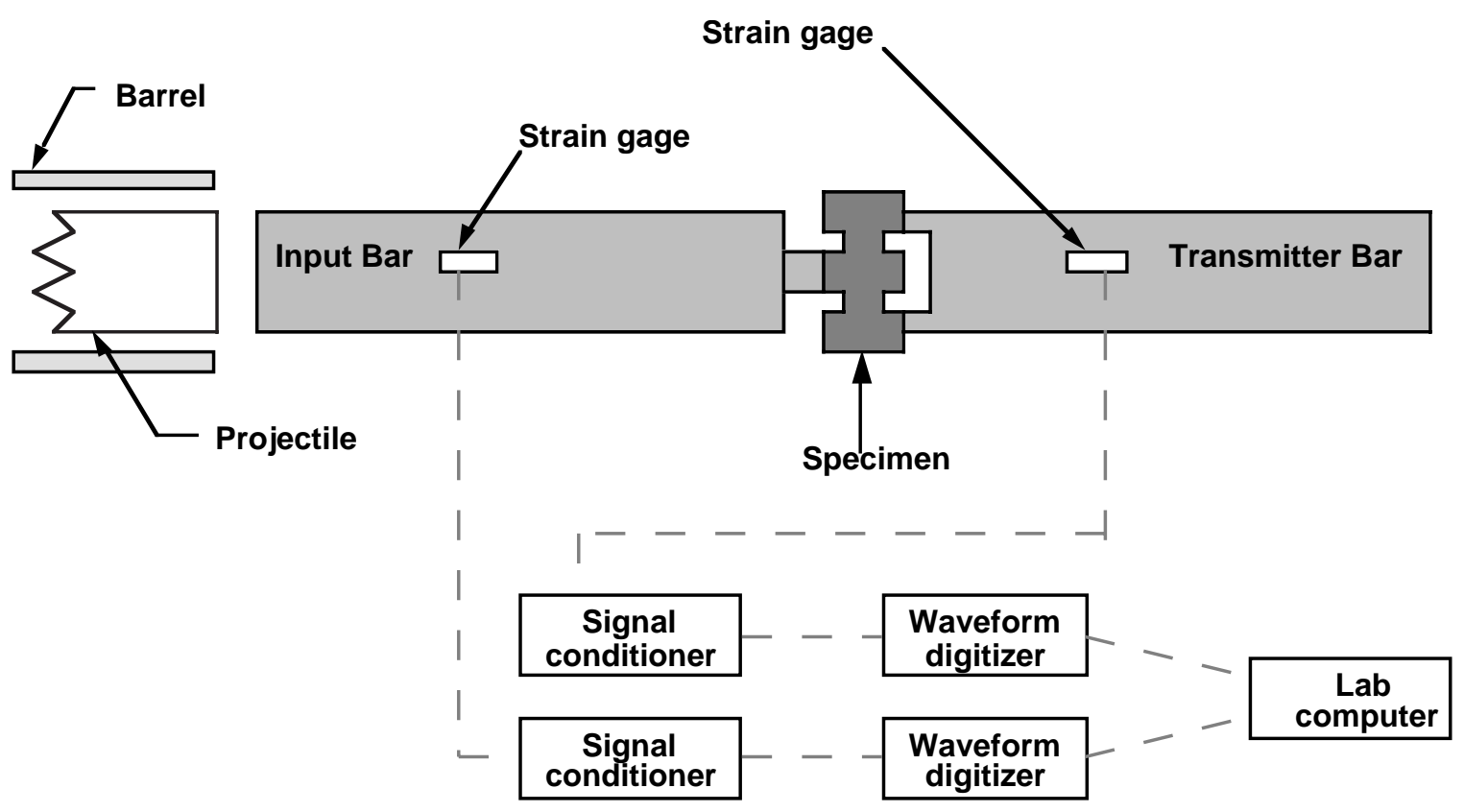

Fig. 2. Schematic diagram of the split Hopkinson pressure bar apparatus used to load the double-notch shear specimen.

\section{Results and Analysis}

Modeling. Simulations of the experiment were performed using the finite element code DYNA2D and the two material models described above - the isotropic EPH model (number 10) and the JC model. The simulations were used as an aid in both specimen and experiment design, as well as to evaluate the material models. For the specimen design studies, three notch configurations were considered. Additional details of the simulations and the results are available in 
references [6, 7]. Previous studies by Harding [8,9] using the double-notch shear specimen have shown that significant plastic bending can occur in the sample, which can cause deviations from the desired strain state of pure shear. The finite element simulations show that these bending effects can be minimized with proper specimen design. The results showed that a specimen containing a square notch (with corner radius equal to .002") on all four sides of the sample had the highest ratio of shear strain to bending and thus was selected for the experimental work. The resulting specimen, which is shown in Fig. 1, is a significant improvement over test sample configurations used by other investigators. Simulations were also done to show the influence of important experimental variables, such as projectile length, incident bar length and strain gage placement. Results here were a significant aid in experiment design and data interpretation.

The deformed configuration for a sample tested with a projectile velocity of 1000 $\mathrm{in} / \mathrm{s}$ is shown in Fig. 3. The specimen is near the point of maximum deformation and bending in the specimen is evident. Contours of effective plastic strain are also shown and illustrate that deformation is concentrated in an arc through the gage section. Similar deformation patterns and failure modes were obtained for both the $\mathrm{JC}$ and the EPH material models. Post-test examination of tested samples confirms the predictions of the simulations and shows that deformation was concentrated in an arc through the gage section. However, the JC model

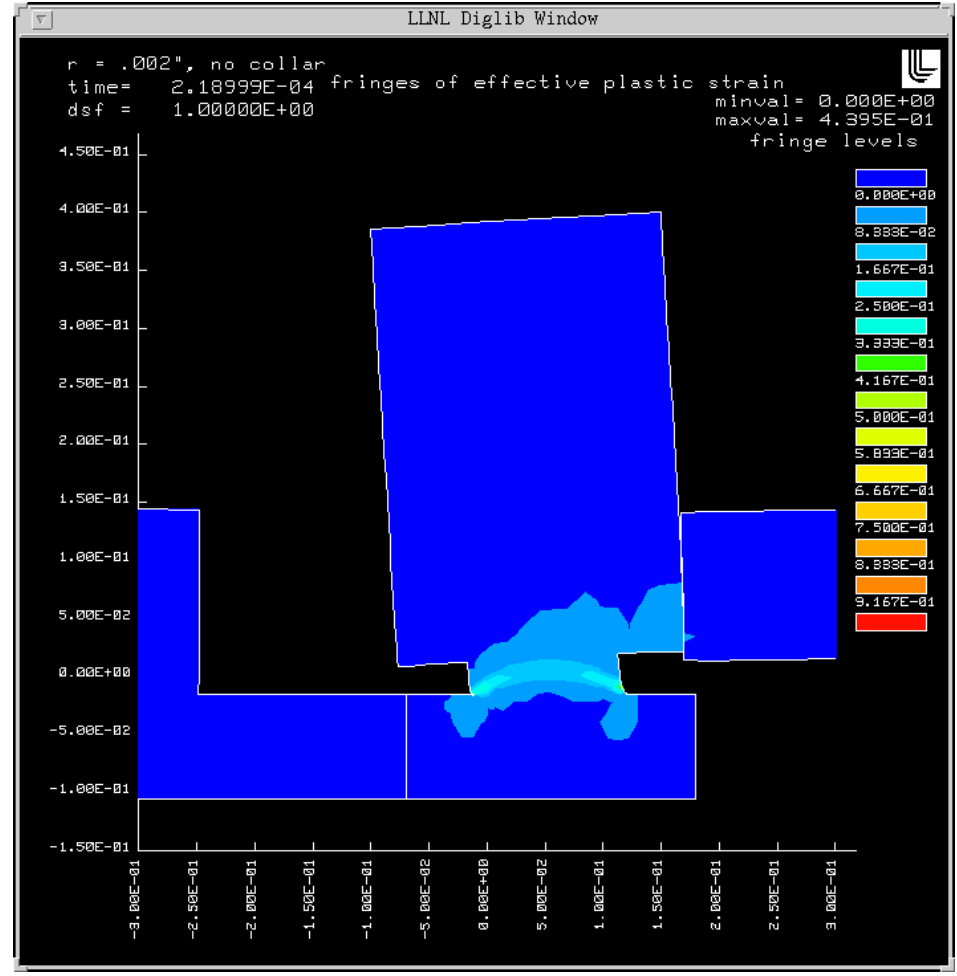

Fig. 3 Simulation results showing the deformed configuration and contours of effective plastic strain for the double-notch shear test. Sample was loaded with a projectile velocity of $1000 \mathrm{in} / \mathrm{s}$.

predicts greater deformation for a given projectile impact velocity. This is primarily a result of the softening caused by temperature increases in the shear zone. 
Experiment results. Experiments were conducted over a range in strain rates from an average shear strain rate of $3.810^{3}$ to $1.110^{4} \mathrm{~s}^{-1}$. The shear stress and shear strain were calculated using Eqns. (3), (4) and (6). The effective stress and effective plastic strain were then determined from the following expressions.

$$
\sigma=\sqrt{3} \tau
$$

and

$$
\varepsilon_{\mathrm{p}}=(\gamma-\tau / \mathrm{G}) / \sqrt{3}
$$

where $\sigma$ is the effective stress, $\varepsilon_{p}$ is the effective plastic strain and $G$ is the shear modulus. The effective stress - effective plastic strain response of the sample is shown in Fig. 4 for a test conducted at $7000 \mathrm{~s}^{-1}$. The adiabatic temperature rise in the sample is also shown in the figure. Sufficient flow localization occurred to promote ductile fracture with a shear strain of about .25 (effective plastic strain of about .14). Despite the limited strains-to-failure, a temperature increase in the sample of about $40^{\circ} \mathrm{C}$ is expected.

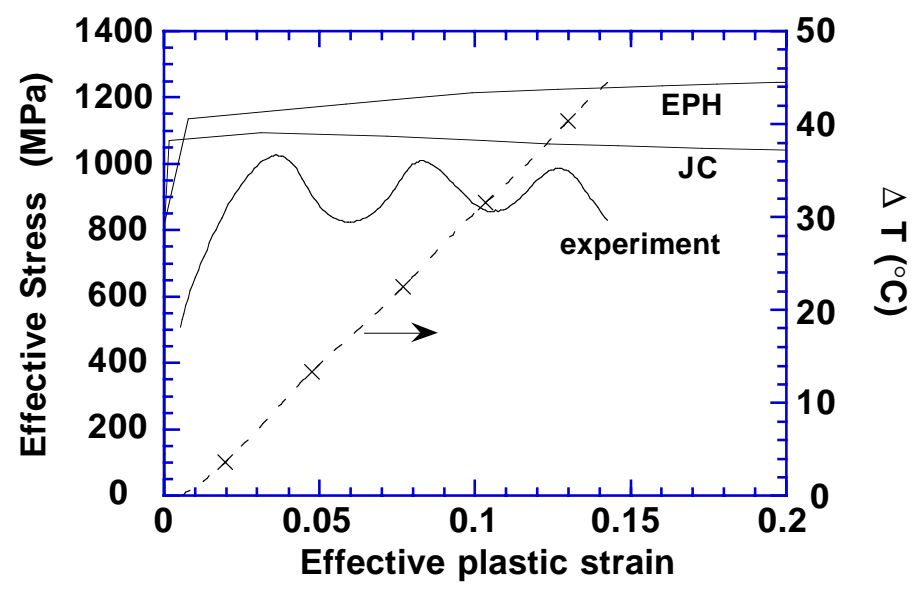

Fig. 4 Simulation results and experimental data of effective stress versus effective plastic strain for the doublenotch shear sample shown in Fig. 1. Results are shown for both the Johnson-Cook (JC) and the elastic-plastichydrodynamic (EPH) material models. Adiabatic temperature increase is shown in the figure. Deformation rate is $7000 \mathrm{~s}^{-1}$.

Figure 5 shows a macro-photograph of a typical failed sample. Examination of samples deformed to strains near, but slightly less than, the failure strain showed cracks at the square corners of the gage section. The cracks resulted from the stress concentration at the corners and were the origins of failure. Final shear 
fracture occurred along an arc in the gage section due to intense plastic shear, which is consist with the predictions of the finite element simulations as shown in Fig. 3. The critical condition for shear fracture was obtained before significant thermal softening could be obtained.

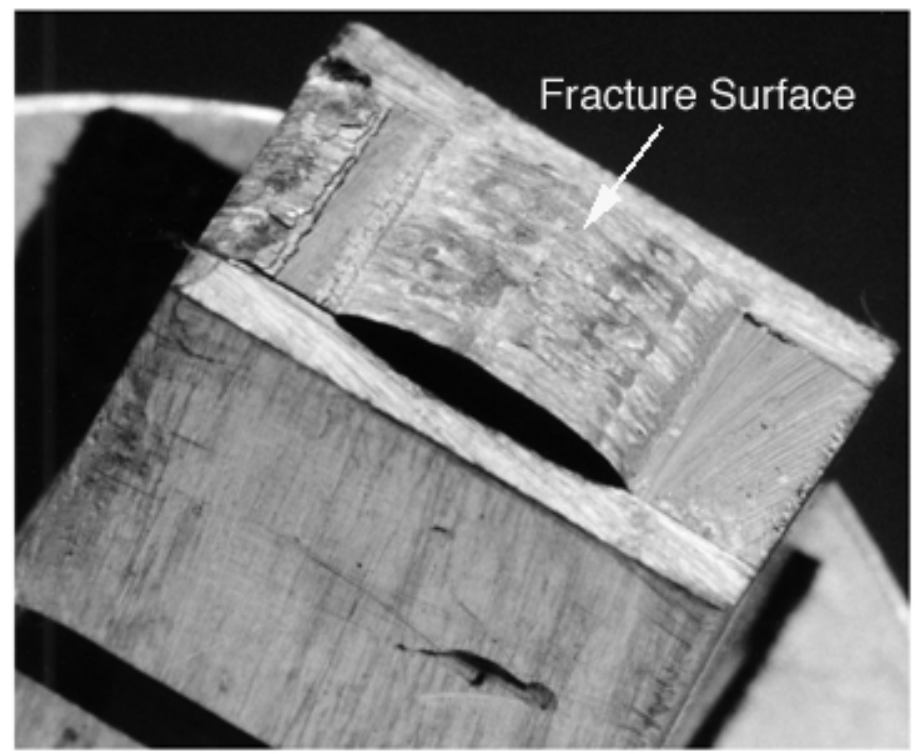

Fig. 5 Macrophotograph of a typical fractured sample. The fracture surface is indicated. Final fracture occurred along an arc in the gage section due to intense plastic shear.

The stress - strain response of the sample as predicted by the simulation was determined for an element in the center of the gage section. Calculations were done for both the EPH and the $\mathrm{JC}$ material models. The results are shown in Fig. 4 and compared against experimental data. The EPH model predicts flow stresses that are typically $200-300 \mathrm{MPa}$ greater than observed experimentally. The calculations also predict a positive work hardening rate that is not observed experimentally. Some of these differences are due to the material model which does not account for adiabatic heat, the resulting increase in temperature and decrease in strength. Experimental data available in the literature shows that the $40^{\circ} \mathrm{C}$ increase in temperature observed here could lower the flow stress by about $100 \mathrm{MPa}$ [10]. For the $\mathrm{JC}$ model, the predicted flow stress in the sample is about $100 \mathrm{MPa}$ higher than observed experimentally. Thus, the JC model shows closer agreement with experimental data than the EPH model. In addition, the JC model shows some thermal softening due to adiabatic heat production, which is consistent with experimental observations. 


\section{Conclusions}

The deformation response of a Ti alloy, Ti-6Al-4V, has been studied during shear localization. The study has involved well-controlled laboratory tests involving a double-notch shear sample. The results have been used to provide a comparison between experiment and the predicted response using DYNA2D and two material models. The primary conclusions from the study are as follows.

1. The deformation of the double-notch shear specimen has been studied using finite element analysis and an optimal specimen design for obtaining shear stress - shear strain data at high rates has been established.

2. The simulations show that deformation is concentrated in an arc through the gage section. Post-test examination of fractured samples shows that the simulations for both the EPH and the JC material models can represent the macroscopic deformation and fracture patterns observed in the sample.

3. For the Ti-6Al-4V alloy studied, shear fractures were obtained with a shear strain of about .25. A temperature increase of about $40^{\circ} \mathrm{C}$ is expected.

4. The EPH model predicted flow stresses that were 200 - $300 \mathrm{MPa}$ higher than experimental data. The calculations also predicted a positive work hardening rate that is not observed experimentally.

5. The JC model predicts flow stresses in the test sample that are closer to experimental data than the EPH model. In addition, the model correctly predicts the thermal softening observed experimentally.

\section{References}

[1] C. Zener and J. H. Hollomon, Effect of Strain Rate Upon Plastic Flow of Steel, Journal of Applied Physics, 15 (January), (1944), 22-32.

[2] G. R. Johnson and W. H. Cook, "A Constitutive Model and Data for Metals Subjected to Large Strains, High Rates and High Temperatures," in Proceedings of the Seventh International Symposium on Ballistics. The Netherlands: The Hague, 1983, 541547.

[3] F. J. Zerilli and R. W. Armstrong, Acta Metallurgica et Materialia, 40 (1992), 1803.

[4] F. J. Zerilli and R. W. Armstrong, Journal of Applied Physics, 68 (1990), 1580.

[5] P. S. Follansbee and U. F. Kocks, Acta Metallurgica, 36 (1988), 81.

[6] B.R. Jorgensen, "Double-Notch Shear Test Analysis using Johnson-Cook Material Properties," 1997. 
[7] B.R. Jorgensen, A Parametric Study of Double-Notch Shear Tests Using Finite Element Analysis, , (1997), .

[8] J. Harding, "Double-Notch Shear testing and Punch Loading," in Metals Handbook - Mechanical Testing, vol. 8, J. R. Newby, Ed. Materials Park, Ohio: ASM International, 1985, 228.

[9] J. Harding and J. Huddart, "The Use of the Double-Notch Shear Test in Determining the Mechanical Properties of Uranium at Very High Rates of Strain," in Mechanical Properties at High Rates of Strain, 1979, J. Harding, Ed. London: The Institute of Physics, 1979, .

[10] D. Eylon, J.R. Newman and J.K. Thorne, "Properties and Selection: Nonferrous Alloys and Special-Purpose Materials," in ASM Handbook, vol. 2. Materials Park, Ohio: ASM International, 1990, 638. 


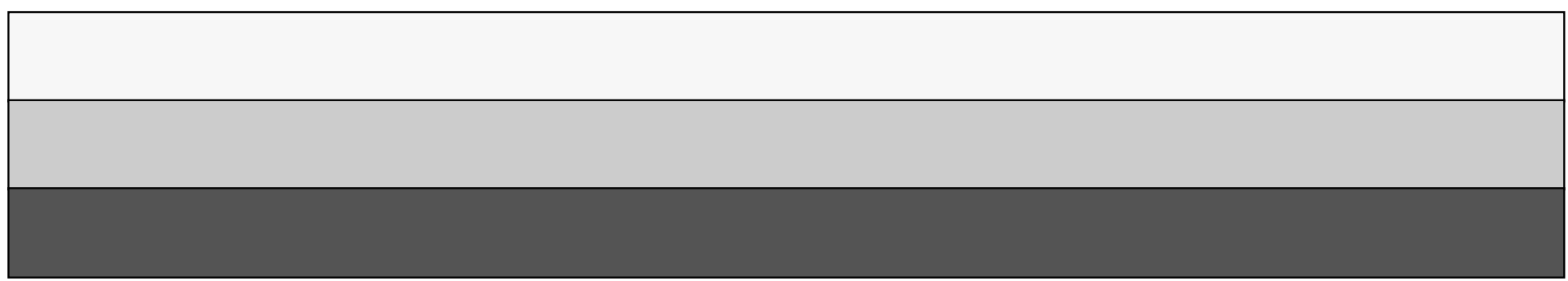

